\title{
PERCEPÇÃO DE VALOR ATRAVÉS DA TÉCNICA LADDERING: UMA ANÁLISE DOS CLIENTES DE CAMINHONETES PICAPES MÉDIAS
}

\author{
Wagner Junior Ladeira \\ Mestre em Administração pela Universidade Federal do Rio Grande do Sul - UFRGS \\ Professor da Universidade do Vale do Rio dos Sinos - UNISINOS \\ E-mail: wjladeira@ ea.ufrgs.br (Brasil)
}

\section{Anderson Zancheta}

Graduado em Administração de Empresas pela Universidade do Vale do Rio dos Sinos UNISINOS

E-mail: anderson_zanc@hotmail.com (Brasil)

\section{RESUMO}

O presente artigo tem como objetivo identificar a percepção de valor nos consumidores de caminhonetes picapes médias. Para isso, foi realizada uma pesquisa qualitativa exploratória com consumidores localizados na região da grande Porto Alegre-RS. A técnica de coleta e análise de dados utilizada foi a laddering. A amostra da pesquisa contou com 13 entrevistados, sendo este número determinado após atingir a saturação teórica das respostas, com a identificação de cadeias completas de valor. A análise dos dados foi dividida em quatro etapas centrais: (a) compilação dos dados isolados em atributos, consequências e valores; (b) elaboração da tabela de ladders, (c) criação da matriz de implicação e mapa hierárquico de valores e (d) definição das percepções dominantes e do relacionamento que gera o valor percebido para os consumidores de caminhonetes picapes médias. Logo após, foram feitas as considerações finais do trabalho.

Palavras-chave: Laddering; Atributos; Consequências; Valor Percebido.

REMark - Revista Brasileira de Marketing, São Paulo, v. 10, n. 1, p 73-96, jan./abr. 2011. 


\section{INTRODUÇÃO}

A percepção é uma dimensão relevante no comportamento humano e caracteriza-se como um conceito central para os teóricos das ciências sociais em diversas áreas que estudam a relação entre atributos e valores (Morschetty, Swoboda, \& Scramm-Klein, 2006; Sherman, Mathur, \& Smith, 1997; Sinha \& Banerjee, 2004). O elemento-chave no processo de percepção é o indivíduo, pois este demanda atributos de acordo com suas expectativas, gerando um valor esperado. Os atributos de um produto ou serviço são, geralmente, avaliados com base em uma gama de informações associadas a ele, e estão dessa forma sob a égide da percepção de valor pelas pessoas (Woodruff \& Gardial, 1996; Zeithaml, 1988).

Dentro de uma perspectiva interacionista o valor envolve uma interação entre algum sujeito e um objeto (Hirschman \& Holbrook, 1992). Assim, o valor depende das características de algum objeto físico ou mental. Na visão de Vargo e Lusch (2004), o valor é sempre idiossincrático, cheio de significado, contextual e empírico, ou seja, é sempre único e definido pelo beneficiário. Desse modo, o valor é baseado na maneira pessoal de ver, sentir e reagir à experiência de uso, resultando em uma atitude, ou em um vínculo emocional.

A relação atributo/valor tradicionalmente atrai vários estudiosos do campo de marketing e, recentemente, o consumo no setor automobilístico no Brasil tem se tornado uma área fértil para o desenvolvimento desses estudos, principalmente em virtude do crescimento deste setor.

Este trabalho traz como objeto de estudo o mercado de picapes médias, que fazem parte do segmento de veículos comerciais leves. Esse mercado, no Brasil, engloba todos os veículos vendidos com peso bruto total de até 3,5 toneladas, o que compreende as picapes pequenas, derivadas dos carros de passeio, as picapes médias, as grandes e as vans, passando pelos furgões e utilitários esportivos.

Para ser mais específico, a classificação de picapes médias como parte do "segmento médio", adotada no continente americano, refere-se aos veículos com comprimento superior a 5 metros e capacidade de carga de uma tonelada. $\mathrm{O}$ setor de caminhonetes picapes médias teve uma participação no setor de comerciais leves com uma porcentagem de 20,15\% em 2008 e de 21,33\% em 2009 (Federação Nacional da Distribuição de Veículos Automotores [FENABRAVE], 2008, 2009). As maiores dimensões desta categoria são $1.555 \mathrm{~mm}$ de comprimento e $1.620 \mathrm{~mm}$ de largura, resultando numa ampla superfície de carga com 2,52 $\mathrm{m}^{2}$. Além de $1.222 \mathrm{~mm}$ de largura

REMark - Revista Brasileira de Marketing, São Paulo, v. 10, n. 1, p 73-96, jan./abr. 2011. 
entre as caixas, tamanho da caçamba $(1,2 \times 0,8 \mathrm{~m})$ na transversal, altura de carga de $779 \mathrm{~mm}$ e à capacidade de carga de até 1,15 tonelada, tem ainda a capacidade de rebocar até 2,8 toneladas. Para melhor ilustrar, seguem alguns exemplos de picapes médias: Mitsubishi L200, Nissan Frontier, Toyota Hilux, Volkswagen Amarok, Chevrolet S10 e Ford Ranger.

Em 2005 o número de vendas neste segmento foi de 56.027 picapes de porte médio. No ano seguinte, foram registradas 61.613 unidades, e, em 2007, 69.974 (Associação Nacional dos Fabricantes de Veículos Automotores ok [ANFAVEA], 2010). A comprovação do crescimento deste segmento pode ser retratada no ano de 2008, com um aumento de 30,41\% e, no ano seguinte 11,26\%, mesmo com a crise financeira que se alastrou pelo mundo (FENABRAVE, 2008, 2009). Com o intuito de entender a relação atributo/valor, encontra-se na academia de marketing uma técnica que procura traduzir os atributos dos produtos e serviços em valores (Kaciak \& Cullen, 2009; Reynolds \& Whitlark, 1995; Veludo-de-Oliveira, Ikeda, \& Campomar, 2006a). Essa técnica desenvolve a cadeia meio-fim para associar atributos (A) de produtos com consequências (C), estabelecendo os valores (V) associados pelo indivíduo no momento do consumo. O seu objetivo é criar associações ACV (escadas ou redes) que representem unidades básicas que motivam o comportamento do consumidor (Kaciak \& Cullen, 2009).

Com base na técnica de coleta e análise de dados laddering, o presente artigo tem como objetivo identificar a percepção de valor nos consumidores de caminhonetes picapes médias. Para tanto, foi realizada uma pesquisa qualitativa exploratória com consumidores localizados na grande Porto Alegre-RS.

A aplicação da entrevista ocorreu entre os dias 26 de março e 19 de abril de 2010, com entrevistas individuais, utilizando a técnica abordada, laddering, através de abordagens pessoais. A amostra da pesquisa contou com 13 entrevistados, sendo este número determinado após atingir a saturação teórica das respostas, com a identificação de cadeias completas de valor. A técnica laddering teve como intenção desenvolver um mapa hierárquico de valor que indica as interrelações entre atributos, consequências e valores pessoais para um dado produto ou categoria de serviço. A análise dos dados foi dividida em quatro etapas centrais: (a) compilação dos dados isolados em atributos, consequências e valores; (b) elaboração da tabela de ladders, (c) criação da matriz de implicação e mapa hierárquico de valores e (d) definição das percepções dominantes e do relacionamento que gera o valor percebido para os consumidores de caminhonetes picapes médias. Logo após, foram feitas as considerações finais do trabalho.

REMark - Revista Brasileira de Marketing, São Paulo, v. 10, n. 1, p 73-96, jan./abr. 2011. 


\section{RELACIONANDO LADDERING E A CADEIA MEIO-FIM}

A técnica laddering se origina nos estudos da psicologia clínica de Hinkle (1965), tendo como intuito entender, através de um modelo, crenças e costumes de uma dada amostra de pessoas. Logo após a sua idealização, a técnica laddering se transformou em uma ferramenta para compreender o significado de certos comportamentos, cujo foco é a investigação de opiniões e atitudes (Grunert \& Grunert, 1995; Kaciak \& Cullen, 2009). Após o trabalho de Hinkle (1965), a técnica laddering cresceu em popularidade na psicologia clínica, estendendo-se para outros campos de conhecimento como arquitetura, tecnologia da informação, gestão organizacional, publicidade e, principalmente, o marketing (Rugg et al., 2002; Veludo-de-Oliveira et al., 2006b). Especificamente no marketing, numerosos estudos têm demonstrado que a técnica laddering é adequada para aplicações, como: segmentação de mercado, promoção de produtos, desenvolvimento de estratégias de publicidade, análise de metas de consumo, expectativas dos clientes e conhecimento do produto por parte dos consumidores (Kaciak \& Cullen, 2009). Em consequência deste fato, hoje em dia, a laddering faz parte de um conjunto de técnicas utilizadas no campo da pesquisa mercadológica, sendo empregada para analisar os modelos de cadeias meio-fim, do inglês models of the Means-End Chain (MEC).

De forma ampla, a laddering pode ser entendida como uma técnica qualitativa, que utiliza entrevista semiestruturada para compreender como os consumidores correlacionam os atributos dos produtos e serviços em valores (Kaciak \& Cullen, 2009; Reynolds \& Whitlark, 1995; Veludo-deOliveira et al., 2006a). Esta técnica incorpora a cadeia meio-fim para associar atributos (A) de produtos com consequências (C), estabelecendo os valores (V) associados pelo indivíduo no momento do consumo. As associações ACV (escadas ou redes) representam muitas vezes as unidades básicas que motivam o comportamento do consumidor (Kaciak \& Cullen, 2009).

Gutman (1982), ao descrever o conceito de laddering destaca esta como uma técnica oneon-one, na qual se faz uma entrevista em profundidade para desenvolver as associações significativas dos atributos dentro da cadeia meio-fim de consumo. Corroborando com os autores Reynolds e Gutman (1988), os quais mencionam que esta envolve a adaptação de uma entrevista, utilizando o formato de uma série de questionamentos que gira em torno da pergunta: Por que é importante para você? Esta questão tem o objetivo expresso de determinar os conjuntos de ligações entre os principais elementos de percepção dos atributos, consequências e valores. A associação

REMark - Revista Brasileira de Marketing, São Paulo, v. 10, n. 1, p 73-96, jan./abr. 2011. 
destes refere-se a uma orientação da percepção que representa combinações de elementos que serve de base para distinção entre tipos diferentes de consumo (Reynolds \& Gutman, 1988). Foote e Lamb (2002) mencionam que esta orientação é modelada como um conjunto de hierarquias, que revelam significados quando associados em uma cadeia (conhecida na literatura também como ladder ou sequência ACV). Observa-se então que um pequeno conjunto de perguntas é usado para extrair conhecimentos e explicações de determinado fenômeno. Os questionamentos concentram-se em determinar conexões entre os atributos, consequências e valores; formando assim conjuntos de cadeias (Reynolds \& Gutman, 1988).

Gutman (1982), ao procurar explicar a cadeia meio-fim, argumenta que quando se estuda o consumo não se pode analisar tão somente a procura pelos atributos do produto, deve-se tentar associá-lo ao conjunto de consequências desejáveis e indesejáveis. Estas consequências são responsáveis por gerar os valores ou um estado final desejado (Radder \& Grunert, 2009; Woodruff \& Gardial, 1996).

\section{MÉTODOS}

O estudo foi desenvolvido com base em uma pesquisa qualitativa e exploratória. A opção pela pesquisa qualitativa se deu pelo fato de esta facilitar a interpretação das particularidades dos comportamentos ou atitudes dos indivíduos. Já o uso da exploratória foi para descobrir as relações entre as partes verificadas no estudo, com o objetivo de familiarizar o pesquisador com as características e as singularidades do tema a ser explorado (Richardson, 1999). Dentro deste contexto, foi realizada a coleta e análise de dados por meio da técnica de encadeamento laddering, tendo como objetivo principal identificar os valores intrínsecos que mobilizam o comportamento dos consumidores de caminhonetes picapes médias.

\subsection{UTILIZAÇÃO DA LADDERING COMO FORMA DE COLETA DOS DADOS}

O objeto de análise deste trabalho foi composto por clientes que consomem caminhonetes picapes médias. A homogeneidade da população é de extrema importância para o estudo uma vez que quanto mais homogênea, menor será a probabilidade de variáveis amostrais influenciarem os resultados. Desse modo, foram selecionados 13 consumidores de caminhonetes picapes médias, de lojas automotivas da região metropolitana de Porto Alegre.

REMark - Revista Brasileira de Marketing, São Paulo, v. 10, n. 1, p 73-96, jan./abr. 2011. 
A aplicação da entrevista ocorreu entre os dias 26 de março e 19 de abril de 2010, com entrevistas individuais utilizando a técnica abordada, laddering, através de abordagens pessoais. As entrevistas tiveram um tempo médio de 50 minutos. $\mathrm{O}$ número de entrevistados foi determinado após atingir a saturação teórica das respostas, com a identificação de cadeias completas de valor, sendo a maior parte do sexo masculino. No aspecto idade, a média entre a amostra desses consumidores ficou em 45 anos, oscilando entre entrevistados com 37 e 56 anos. Já quanto à escolaridade, apenas 3 respondentes não cursaram o ensino superior, dentre os que o cursaram encontram-se a maioria, e apenas um entrevistado ainda está cursando graduação, tendo somente 2 entrevistados com pós-graduação concluída.

Com relação à compra de uma picape média observa-se que todos os entrevistados têm este produto há pelo menos três anos. Sendo importante ressaltar que pelo menos 69,2\% dos entrevistados já possuíram anteriormente outras picapes.

\subsection{UTILIZAÇÃO DA LADDERING COMO FORMA DE ANALISAR OS DADOS}

A técnica laddering tem como intenção desenvolver um mapa hierárquico de valor que indica as inter-relações entre atributos, consequências e valores pessoais para um dado produto ou categoria de serviço (Reynolds \& Gutman, 1988). Assim, para obter os elementos citados, a técnica laddering exige alguns formatos de questionamentos específicos para os atributos, consequências e valores, que facilitam a aplicação do instrumento, extraindo de uma forma mais produtiva os dados necessários.

Inicialmente, pergunta-se ao entrevistado que tipos de características seriam úteis para descrever ou distinguir diferentes produtos ou serviços de uma dada categoria de interesse. O objetivo dessa forma de questionamento é fazer com que o respondente mencione os principais atributos do produto. A partir da resposta inicial dos entrevistados, que se refere aos atributos, começa a ser construída a hierarquia de valor, quando o pesquisador discute as razões das preferências apontadas pelo respondente e, com isso, consegue levar as respostas a um nível de abstração correspondente às consequências e valores pessoais. Através de perguntas repetidas e interativas, os respondentes são encorajados a se aprofundar na discussão sobre atributos, indicando, paulatinamente, consequências e valores (Radder \& Grunert, 2009; Reynolds \& Gutman, 1988; Veludo-de-Oliveira et al., 2006b; Woodruff \& Gardial, 1996).

REMark - Revista Brasileira de Marketing, São Paulo, v. 10, n. 1, p 73-96, jan./abr. 2011. 


\section{ANÁLISE DE RESULTADOS}

Neste capítulo, são apresentados os resultados obtidos a partir da aplicação da pesquisa com a utilização do método laddering, e a análise deste se estrutura da seguinte maneira: (a) compilação dos dados isolados em atributos, consequências e valores; (b) elaboração da tabela de ladders, (c) criação da matriz de implicação e mapa hierárquico de valores e (d) definição das percepções dominantes e do relacionamento que gera o valor percebido nos utilitários de caminhonetes picapes médias.

\subsection{ELEMENTOS ISOLADOS QUE EXPRESSAM AS LADDERS}

Para a análise do conteúdo foi realizada na transcrição das entrevistas a identificação dos componentes da cadeia e, logo após o término da análise preliminar de cada uma das entrevistas, foi elaborado o quadro da consolidação dos elementos, eliminando com isso termos de significados semelhantes. Neste quadro foram extraídos do conteúdo da pesquisa frases que expressam os atributos, consequências ou valores.

Os atributos estão no nível mais concreto da cadeia, compostos por características (componentes, partes, entre outros) que produzirão as consequências desejadas pelo consumidor. $\mathrm{Na}$ pesquisa realizada foram identificados 11 atributos, que estão classificados do número 1 ao 11 , no quadro 1. Já as consequências são os pacotes de benefícios que os consumidores podem descrever em um contexto de consumo. $\mathrm{Na}$ análise realizada foram identificadas 18 consequências que foram apresentadas de forma categorizada do número 12 ao 30. Já os valores estão no nível mais alto da abstração da cadeia, pois se tratam de elementos subjetivos e individuais de cada sujeito. No total foram elencados 6 valores terminais que são apresentados de forma categorizada com a representação das frases originadas na pesquisa, do número 31 ao 46.

REMark - Revista Brasileira de Marketing, São Paulo, v. 10, n. 1, p 73-96, jan./abr. 2011. 


\begin{tabular}{|c|c|c|c|}
\hline CÓD. & CATEGORIZAÇÃO & DESCRIÇÕES & ENTREV. \\
\hline 1 & Marca & $\begin{array}{l}\text { Credibilidade da marca; disponibilidade de peças; valor de } \\
\text { revenda. }\end{array}$ & $4 ; 6 ; 8$ \\
\hline 2 & Design & Estilo da caminhonete picape; linhas; cores; curvas. & $6 ; 12$ \\
\hline 3 & Conforto & $\begin{array}{l}\text { Bancos confortáveis, Itens de tecnologia; espaço entre os } \\
\text { passageiros. }\end{array}$ & $11 ; 4$ \\
\hline 4 & Robustez & Durabilidade de motor e peças/ Resistência a todo tipo de uso. & $4 ; 7 ; 12$ \\
\hline 5 & Segurança & Itens de segurança; estabilidade; sensação de veículo confiável. & $6 ; 11$ \\
\hline 6 & Tamanho da Caçamba & $\begin{array}{l}\text { Facilidade de carregar todo tipo de carga; carregar mais peso; } \\
\text { maior espaço de carga. }\end{array}$ & $5 ; 7$ \\
\hline 7 & Desempenho & $\begin{array}{l}\text { Estabilidade em curvas; consumo de combustível; retomada de } \\
\text { velocidade; força. }\end{array}$ & $10 ; 12$ \\
\hline 8 & Acessórios & $\begin{array}{l}\text { Opcionais internos e externos do veículo (Ex: quebra-mato, santo } \\
\text { antônio, estribo, capota marítima, porta-objetos, air bag, etc.). }\end{array}$ & $13 ; 7 ; 9$ \\
\hline 9 & Tamanho & $\begin{array}{l}\text { Dimensões da caminhonete, tamanho das rodas, peso, espaço } \\
\text { interno. }\end{array}$ & $2 ; 5 ; 8 ; 10$ \\
\hline 10 & Altura & Distância da caminhonete em relação ao solo. & $10 ; 11$ \\
\hline 11 & Preço de manutenção & Preço de peças; custo de mão de obra; disponibilidade de peças. & $1 ; 4 ; 9$ \\
\hline 12 & Viajar mais & Ter a possibilidade de viajar com maior frequência. & $13 ; 2 ; 7$ \\
\hline 13 & Status & Categoria social que determinada caminhonete representa. & $4 ; 5 ; 10$ \\
\hline 14 & $\begin{array}{l}\text { Reconhecimento } \\
\text { Social }\end{array}$ & $\begin{array}{l}\text { Ser uma pessoa reconhecida pela sociedade, possuindo respeito e } \\
\text { admiração. }\end{array}$ & $\begin{array}{l}4 ; 6 ; 7 ; 10 ; \\
11 ; 12 ; 13\end{array}$ \\
\hline 15 & Confiar na picape & $\begin{array}{l}\text { Confiança que a caminhonete executará determinado comando de } \\
\text { forma eficiente e precisa. }\end{array}$ & $2 ; 13 ; 9$ \\
\hline
\end{tabular}

REMark - Revista Brasileira de Marketing, São Paulo, v. 10, n. 1, p 73-96, jan./abr. 2011. 


\begin{tabular}{|c|c|c|c|}
\hline 16 & Visual atrativo & Estética; beleza; satisfação visual; formato ideal, visual moderno. & $3 ; 10$ \\
\hline 17 & Espaço interno & Dimensões do interior do veículo. & $11 ; 13 ; 6$ \\
\hline 18 & Praticidade & $\begin{array}{l}\text { Funcionalidade e versatilidade que uma caminhonete picape } \\
\text { oferece no cotidiano. }\end{array}$ & $8 ; 6 ; 11$ \\
\hline 19 & Imposição no trânsito & Respeitado no trânsito; ter seu espaço respeitado. & $1 ; 7 ; 10$ \\
\hline 20 & $\begin{array}{l}\text { Melhor visão para } \\
\text { dirigir }\end{array}$ & Permite ao condutor uma maior visibilidade da estrada. & $1 ; 3 ; 2$ \\
\hline 21 & Durabilidade & Capacidade de suportar adversidades; resistir. & $10 ; 7$ \\
\hline 22 & Qualidade & $\begin{array}{l}\text { Percepção de que alguns atributos interferem diretamente na } \\
\text { qualidade de uma caminhonete; grau de excelência de um } \\
\text { produto. }\end{array}$ & $13 ; 2$ \\
\hline 23 & Maior cap. de carga & $\begin{array}{l}\text { Carregar mais bagagens e objetos maiores sem se preocupar com } \\
\text { o espaço. }\end{array}$ & $9 ; 3 ; 5$ \\
\hline 24 & Tranquilidade & Não se incomodar; sem estresse; relaxar. & $12 ; 1$ \\
\hline 25 & Potência & Mover-se com agilidade no trânsito; força do motor. & $\begin{array}{l}12 ; 13 ; 8 \\
\quad 9 ; 5\end{array}$ \\
\hline 26 & Satisfação & Estar satisfeito. & $11 ; 13$ \\
\hline 27 & Redução de riscos & $\begin{array}{l}\text { Caminhonete que proporciona maior segurança para os } \\
\text { motoristas. }\end{array}$ & $13 ; 2 ; 1$ \\
\hline 28 & Custo-benefício & $\begin{array}{l}\text { Valor pago pela manutenção e outros gastos da caminhonete que } \\
\text { sejam compatíveis com o investimento. }\end{array}$ & $4 ; 12 ; 13$ \\
\hline 29 & Dirigibilidade & Facilidade de guiar a caminhonete. & $11 ; 12 ; 13 ; 6$ \\
\hline 30 & Autorreconhecimento & Reconhecer o seu estilo e personalidade. & $5 ; 9 ; 12$ \\
\hline 31 & Prazer & Aproveitar a vida; sentir-se bem. & $10 ; 13$ \\
\hline
\end{tabular}

REMark - Revista Brasileira de Marketing, São Paulo, v. 10, n. 1, p 73-96, jan./abr. 2011. 
Percepção de Valor através da Técnica Laddering: Uma Análise dos Clientes de Caminhonetes

Picapes Médias

\begin{tabular}{|c|l|l|c|}
\hline 32 & Integração & $\begin{array}{l}\text { Relações pessoais; facilita a convivência; interagir; socialização; } \\
\text { Integrar o grupo; Confraternizar. }\end{array}$ & $\begin{array}{c}2 ; 7 ; 10 ; 4 ; \\
8 ; 11\end{array}$ \\
\hline $\mathbf{3 3}$ & Estar seguro & Sentimento de estar protegido; confiar no veículo. & $1 ; 7 ; 12$ \\
\hline $\mathbf{3 4}$ & Ser funcional & Versatilidade que uma caminhonete picape oferece no cotidiano. & $6 ; 5$ \\
\hline $\mathbf{3 5}$ & Felicidade & Sensação de alegria; momentos de alegria. & $13 ; 2 ; 6$ \\
\hline $\mathbf{3 6}$ & Auto-estima & $\begin{array}{l}\text { Sentir-se bem-sucedido; moral elevada; confiança em si próprio; } \\
\text { orgulho de si mesmo. }\end{array}$ & $9 ; 3$ \\
\hline
\end{tabular}

Quadro 1- Categorização e Codificação dos Valores Identificados.

\subsection{ELABORAÇÃO DAS LADDERS}

Após a categorização e codificação dos atributos, consequências e valores, foi realizada a compilação destes elementos e em seguida a formação das ladders, que no total foram discriminadas em 15. Esses dados foram organizados no quadro de número 2.

\begin{tabular}{|c|c|c|c|c|}
\hline LADDER & ATRIBUTO & \multicolumn{2}{|c|}{ CONSEQUENCIAS } & VALORES \\
\hline $\mathbf{1}$ & Marca & Confiar na picape & Qualidade & Estar seguro \\
\hline $\mathbf{2}$ & Marca & Status & Reconhecimento social & Autoestima \\
\hline $\mathbf{3}$ & Segurança & Confiar na picape & Viajar mais & Integração \\
\hline $\mathbf{4}$ & Segurança & Redução de risco & Tranquilidade & Estar seguro \\
\hline $\mathbf{5}$ & Desempenho & Potência & Confiar na picape & Autoestima \\
\hline
\end{tabular}

REMark - Revista Brasileira de Marketing, São Paulo, v. 10, n. 1, p 73-96, jan./abr. 2011. 
Wagner Junior Ladeira \& Anderson Zancheta

\begin{tabular}{|c|c|c|c|c|}
\hline 7 & Design & Visual atrativo & Status & Autoestima \\
\hline 8 & Design & Autorreconhecimento & Reconhecimento social & Prazer \\
\hline 9 & Preço da manutenção & Custo-benefício & Satisfação & Felicidade \\
\hline 10 & Conforto & Espaço interno & Visual atrativo & Prazer \\
\hline 11 & Conforto & Tranquilidade & Viajar mais & Integração \\
\hline 12 & Acessórios & Redução de risco & Visual atrativo & Prazer \\
\hline 13 & Tamanho da caçamba & Capacidade de carga & Praticidade & Ser funcional \\
\hline 14 & Altura & Visão para dirigir & Dirigibilidade & Ser funcional \\
\hline 15 & Tamanho & Espaço interno & Imposição no trânsito & Autoestima \\
\hline
\end{tabular}

\section{Quadro 2 - Ladders.}

\subsection{MATRIZ DE IMPLICAÇÃO E A CONSTRUÇÃO DO MAPA HIERÁRQUICO}

De modo a auxiliar na apreciação dos elementos que possuem mais citações e relações com os outros, foi realizada uma matriz de implicação, que representa o número de vezes que cada elemento leva a outro (Reynolds \& Gutman, 1988). Para montagem desta matriz, são considerados dois tipos de relações possíveis entre os elementos: (1) as relações diretas, ou seja, entre elementos adjacentes nos ladders; e (2) as indiretas, que correspondem às relações entre elementos dos ladders com um ou mais elementos entre elas. Portanto, estas relações são descritas abaixo na seguinte notação: XX.YY sendo XX as relações diretas, e YY as relações indiretas.

REMark - Revista Brasileira de Marketing, São Paulo, v. 10, n. 1, p 73-96, jan./abr. 2011. 
Percepção de Valor através da Técnica Laddering: Uma Análise dos Clientes de Caminhonetes Picapes Médias

\begin{tabular}{|c|c|c|c|c|}
\hline \multicolumn{2}{|c|}{ CÓDIGO } & ATRIBUTOS & CONSEQUÊNCIAS & VALORES \\
\hline \multirow{11}{*}{ 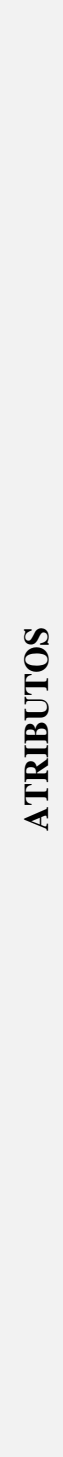 } & 01 & & $\begin{array}{c}\text { 12(00.01); 13(06.00); 14(00.06); 15(03.00); } \\
\text { 16(00.01); 21(0.01); 22(00.03) }\end{array}$ & $\begin{array}{c}31(00.01) ; 33(00.07) \\
36(00.03)\end{array}$ \\
\hline & 02 & & 13(00.07); 14(00.03); 16(07.00), 30(03.00) & 31(00.03); 36(00.07) \\
\hline & $\mathbf{0 3}$ & & $\begin{array}{c}12(00.03) ; 13(00.01) ; 16(00.06) \\
19(00.01) ; 24(03.00)\end{array}$ & $\begin{array}{c}31(00.06) ; 32(00.03) \\
33(00.01)\end{array}$ \\
\hline & 04 & & $12(00.01) ; 15(00.01) ; 21(04.00) ; 22(00.04)$ & $33(00.04)$ \\
\hline & 05 & & $\begin{array}{c}12(00.05) ; 15(05.00) ; 16(00.01) ; 24(00.01) ; \\
27(07.00)\end{array}$ & $\begin{array}{c}\text { 32(00.05); 33(00.07); } \\
\text { 36(00.01) }\end{array}$ \\
\hline & 06 & & 18 (00.05); $23(05.00)$ & $36(00.05)$ \\
\hline & 07 & & $\begin{array}{c}13(00.01) ; 15(00.05) ; 22(00.01) ; 24(00.01) ; \\
25(05.00)\end{array}$ & $36(00.05)$ \\
\hline & 08 & & $12(00.01) ; 13(00.01) ; 16(00.03) ; 27(03.00)$ & $31(00.03)$ \\
\hline & 09 & & $\begin{array}{c}13(00.01) ; 14(00.01) ; 16(00.01) ; 17(06.00) ; \\
19(00.06)\end{array}$ & $36(00.06)$ \\
\hline & 10 & & $20(03.00) ; 29(00.03)$ & $34(00.03)$ \\
\hline & 11 & & $26(00.02) ; 28(02.00)$ & $35(00.02)$ \\
\hline \multirow{2}{*}{$\begin{array}{l}0 \\
0 \\
z \\
z \\
0 \\
0 \\
0 \\
0 \\
0 \\
0 \\
0 \\
0\end{array}$} & 12 & $\begin{array}{l}01(00.01) \\
03(00.03) \\
04(00.01) \\
05(00.05) \\
08(00.01)\end{array}$ & $15(05.00) ; 21(00.01) ; 24(00.03) ; 25(00.01)$ & $\begin{array}{c}32(05.00) ; 33(00.01) \\
36(00.01)\end{array}$ \\
\hline & 13 & $\begin{array}{c}01(06.00) \\
02(00.07) \\
03(00.01) \\
07(00.01) \\
08(00.01) \\
09(00.01)\end{array}$ & 14(06.00); 16(07.00); 17(00.01); 30(00.01) & 31(00.01); 36(07.06) \\
\hline
\end{tabular}

REMark - Revista Brasileira de Marketing, São Paulo, v. 10, n. 1, p 73-96, jan./abr. 2011. 
Wagner Junior Ladeira \& Anderson Zancheta

\begin{tabular}{|c|c|c|c|}
\hline 14 & $\begin{array}{l}01(00.06) \\
02(00.03) \\
09(00.01)\end{array}$ & $\begin{array}{c}13(06.00) ; 16(00.01) ; 17(00.01) ; 27(00.01) \\
30(03.00)\end{array}$ & $31(03.00) ; 36(06.00)$ \\
\hline 15 & $\begin{array}{c}01(03.00) \\
04(00.01) \\
05(05.00) \\
07(00.05)\end{array}$ & 12(05.00); 22(03.00); 24(00.01); 25(05.00) & $\begin{array}{c}32(00.05) ; 33(00.03) ; \\
36(05.00)\end{array}$ \\
\hline 16 & $\begin{array}{l}01(00.01) \\
03(00.06) \\
05(00.01) \\
08(00.03) \\
09(00.01)\end{array}$ & $\begin{array}{c}13(07.00) ; 14(00.01) ; 17(06.00) ; 19(00.01) ; \\
27(03.00)\end{array}$ & $31(09.00) ; 36(00.07)$ \\
\hline 17 & $09(06.00)$ & $13(00.01) ; 16(06.00) ; 19(06.00)$ & $31(00.06) ; 36(00.06)$ \\
\hline 18 & $06(00.05)$ & $23(05.00)$ & $34(05.00)$ \\
\hline 19 & $\begin{array}{l}03(00.01) \\
09(00.06)\end{array}$ & $\begin{array}{c}13(00.01) ; 14(00.01) ; 16(00.01) ; 17(06.00) \\
30(00.01)\end{array}$ & $31(00.01) ; 36(06.00)$ \\
\hline 20 & $10(03.00)$ & $29(03.00)$ & $34(00.03)$ \\
\hline 21 & $\begin{array}{l}01(0.01) \\
04(04.00)\end{array}$ & 12(00.01); 15(00.01); 22(04.00); 24(00.01) & $\begin{array}{c}32(00.01) ; 33(00.04) ; \\
36(00.01)\end{array}$ \\
\hline 22 & $\begin{array}{l}01(00.03) \\
04(00.04) ; \\
07(00.01)\end{array}$ & 12(00.01); 15(03.00); 21(04.00); 25(00.01) & $\begin{array}{c}32(00.01) ; 33(04.03) ; \\
36(00.01)\end{array}$ \\
\hline 23 & $06(05.00)$ & 18(05.00) & $34(05.00)$ \\
\hline 24 & $\begin{array}{l}03(03.00) \\
07(00.01)\end{array}$ & $\begin{array}{c}12(03.00) ; 14(00.01) ; 21(00.01) ; 22(00.01) ; \\
25(00.01) ; 27(07.00)\end{array}$ & $\begin{array}{c}32(00.03) ; 33(07.00) ; \\
36(00.01)\end{array}$ \\
\hline 25 & $\begin{array}{c}05(00.01) \\
07(05.00)\end{array}$ & 12(00.01); 15(05.00); 21(00.01); 22(00.01) & $\begin{array}{l}32(00.01) ; 33(00.01) ; \\
36(00.05)\end{array}$ \\
\hline 26 & $11(00.02)$ & $28(02.00)$ & $35(02.00)$ \\
\hline 27 & $\begin{array}{l}05(07.00) \\
08(03.00)\end{array}$ & $\begin{array}{c}12(00.01) ; 13(00.01) ; 14(00.01) ; 16(03.00) \\
24(07.00) ; 30(00.01)\end{array}$ & $\begin{array}{l}31(00.03) ; 32(00.01) ; \\
33(00.07) ; 36(00.01)\end{array}$ \\
\hline
\end{tabular}

REMark - Revista Brasileira de Marketing, São Paulo, v. 10, n. 1, p 73-96, jan./abr. 2011. 
Percepção de Valor através da Técnica Laddering: Uma Análise dos Clientes de Caminhonetes

Picapes Médias

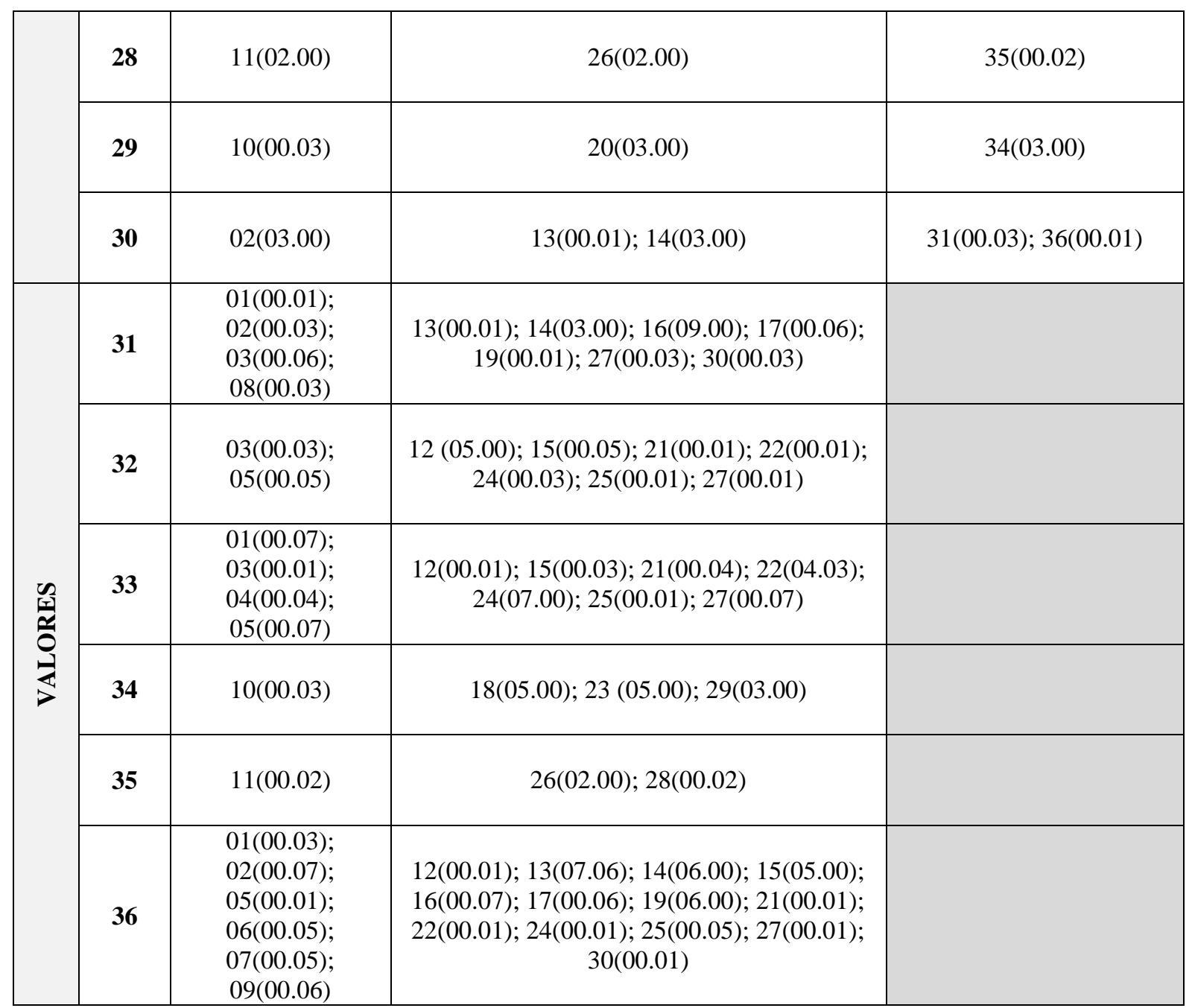

Quadro 3 - Simplificação Gráfica da Matriz de Implicação.

Essa matriz retrata quantitativamente as associações entre os elementos na formação das cadeias, seja diretamente, seja indiretamente. O quadro a seguir resume a quantidade de relações que cada elemento teve, para assim facilitar a visualização dos que tiveram um número de implicações superior.

REMark - Revista Brasileira de Marketing, São Paulo, v. 10, n. 1, p 73-96, jan./abr. 2011. 
Wagner Junior Ladeira \& Anderson Zancheta

\begin{tabular}{|c|c|c|c|c|}
\hline $\mathrm{A} / \mathrm{C} / \mathrm{V}$ & CÓDIGO & ELEMENTO & DE & PARA \\
\hline 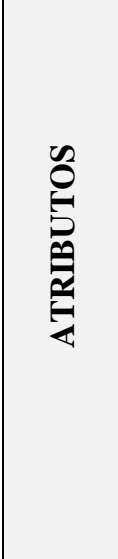 & $\begin{array}{c}1 \\
2 \\
3 \\
4 \\
5 \\
6 \\
7 \\
8 \\
9 \\
10 \\
11\end{array}$ & $\begin{array}{c}\text { Marca } \\
\text { Design } \\
\text { Conforto } \\
\text { Robustez } \\
\text { Segurança } \\
\text { Tamanho da Caçamba } \\
\text { Desempenho } \\
\text { Acessórios } \\
\text { Tamanho } \\
\text { Altura } \\
\text { Preço de manutenção }\end{array}$ & $\begin{array}{l}09.24 \\
10.19 \\
09.21 \\
04.10 \\
12.20 \\
05.10 \\
05.13 \\
03.08 \\
06.15 \\
03.06 \\
02.04\end{array}$ & $\begin{array}{l}00.00 \\
00.00 \\
00.00 \\
00.00 \\
00.00 \\
00.00 \\
00.00 \\
00.00 \\
00.00 \\
00.00 \\
00.00\end{array}$ \\
\hline 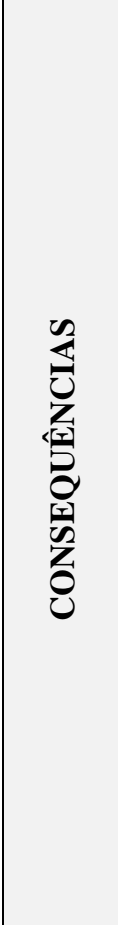 & $\begin{array}{l}12 \\
13 \\
14 \\
15 \\
16 \\
17 \\
18 \\
19 \\
20 \\
21 \\
22 \\
23 \\
24 \\
25 \\
26 \\
27 \\
28 \\
29 \\
30\end{array}$ & $\begin{array}{c}\text { Viajar mais } \\
\text { Status } \\
\text { Rec. Social } \\
\text { Confiar na picape } \\
\text { Visual atrativo } \\
\text { Espaço interno } \\
\text { Praticidade } \\
\text { Imposição no trânsito } \\
\text { Melhor visão para dirigir } \\
\text { Durabilidade } \\
\text { Qualidade } \\
\text { Maior capacidade de carga } \\
\text { Tranquilidade } \\
\text { Potência } \\
\text { Satisfação } \\
\text { Redução de riscos } \\
\text { Custo-benefício } \\
\text { Dirigibilidade } \\
\text { Autorreconhecimento }\end{array}$ & $\begin{array}{l}13.04 \\
20.09 \\
18.03 \\
17.09 \\
25.09 \\
18.07 \\
10.00 \\
12.05 \\
03.03 \\
04.09 \\
11.07 \\
05.05 \\
17.08 \\
05.10 \\
04.00 \\
10.18 \\
02.02 \\
06.00 \\
03.05\end{array}$ & $\begin{array}{l}08.16 \\
19.14 \\
09.14 \\
21.07 \\
23.14 \\
24.02 \\
05.05 \\
06.08 \\
06.00 \\
08.04 \\
07.10 \\
10.00 \\
13.04 \\
10.03 \\
02.02 \\
20.01 \\
04.00 \\
03.03 \\
06.03\end{array}$ \\
\hline 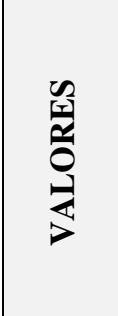 & $\begin{array}{l}31 \\
32 \\
33 \\
34 \\
35 \\
36\end{array}$ & $\begin{array}{c}\text { Prazer } \\
\text { Integração } \\
\text { Estar seguro } \\
\text { Ser funcional } \\
\text { Felicidade } \\
\text { Autoestima }\end{array}$ & $\begin{array}{l}00.00 \\
00.00 \\
00.00 \\
00.00 \\
00.00 \\
00.00\end{array}$ & $\begin{array}{l}12.27 \\
05.20 \\
11.38 \\
08.11 \\
02.04 \\
24.42\end{array}$ \\
\hline
\end{tabular}

Quadro 03 - Síntese da matriz de implicação.

REMark - Revista Brasileira de Marketing, São Paulo, v. 10, n. 1, p 73-96, jan./abr. 2011. 
A partir desse quadro é possível enfatizar os itens que tiveram mais associações dentre todas as ladders, colaborando para a avaliação e análise dos valores dominantes. Sendo o primeiro deles a Autoestima (36), que foi um dos que mais tiveram relações diretas (24) e o que mais teve relações indiretas (42), demonstrando ser um objetivo a ser buscado pelos entrevistados, que sob diversas ópticas mencionaram este valor. O Visual atrativo (16) foi o item com mais relações diretas (25) e menos indiretas (9), já o Prazer (31) possui (27) relações indiretas e (12) diretas. Isto mostra como a autoestima é importante para os consumidores, estes precisam estar bem consigo mesmos, com a sociedade, para se sentirem orgulhosos. Pode-se perceber que com a autoestima baixa valores como o prazer não são atingidos facilmente pelos entrevistados, que, como veremos a seguir relacionam o conforto, design e visual atrativo da sua picape para obter esses valores principais.

Os itens Design (02), com (10) relações diretas e (19) indiretas; Conforto (03) com (09) diretas e (21) indiretas; o Status (13) com (20) diretas e (09) indiretas; juntamente com o Reconhecimento social (14), que teve (18) relações diretas e (03) indiretas, e Integração (32) com (05) diretas e (20) indiretas são itens caracterizados como muito importantes pelos entrevistados, e que são considerados importantes também pelo entrevistador, uma vez que interferem na imagem que a sociedade faz da picape e de seu proprietário. A entrevista de profundidade possibilita que o entrevistador se aprofunde nos sentimentos e valores dos respondentes, o que proporcionou vislumbrar quanto a opinião pública (tanto familiares, amigos e sociedade em geral) é importante e influencia na tomada de decisão do consumidor.

Já os itens Segurança (05) com (12) relações diretas e (20) indiretas, juntamente com os valores Estar seguro (33) com (11) diretas e (38) indiretas; Espaço interno (17) com (18) relações diretas e (07) indiretas; Tranquilidade (24) com (17) diretas e (08) indiretas; Confiar na picape (15) com (17) diretas e (09) indiretas são expressos pelos consumidores mais diretamente relacionados à vida familiar, à segurança que a picape proporciona e ao fato da sua funcionalidade no dia a dia e nos momentos como viagens e passeios com a família e amigos. De acordo com os entrevistados, estes valores proporcionam tranquilidade ao utilizar sua picape, incentivando os proprietários a sair mais, viajar mais, como demonstra o valor Viajar mais (12), que teve (13) relações diretas e (04) indiretas.

O mapa hierárquico de valor consiste em demonstrar graficamente quais os elementos do produto conduzem a determinado valor pessoal. Para isso, segundo Veludo-de-Oliveira (2006a), não há a necessidade de mapear todas as relações entre atributos, sendo necessário, portanto,

REMark - Revista Brasileira de Marketing, São Paulo, v. 10, n. 1, p 73-96, jan./abr. 2011. 
identificar as principais cadeias, que são filtradas de acordo com um ponto de corte predeterminado, que se refere ao conjunto de ligações diretas e indiretas que os elementos possuem. Neste caso foi utilizado o ponto de corte 8 para ligações diretas e 4 para ligações indiretas, e as relações principais estão balizadas em negrito, conforme o mapa hierárquico de valor.

Figura 1 - Mapa Hierárquico de Valores Simplificados.

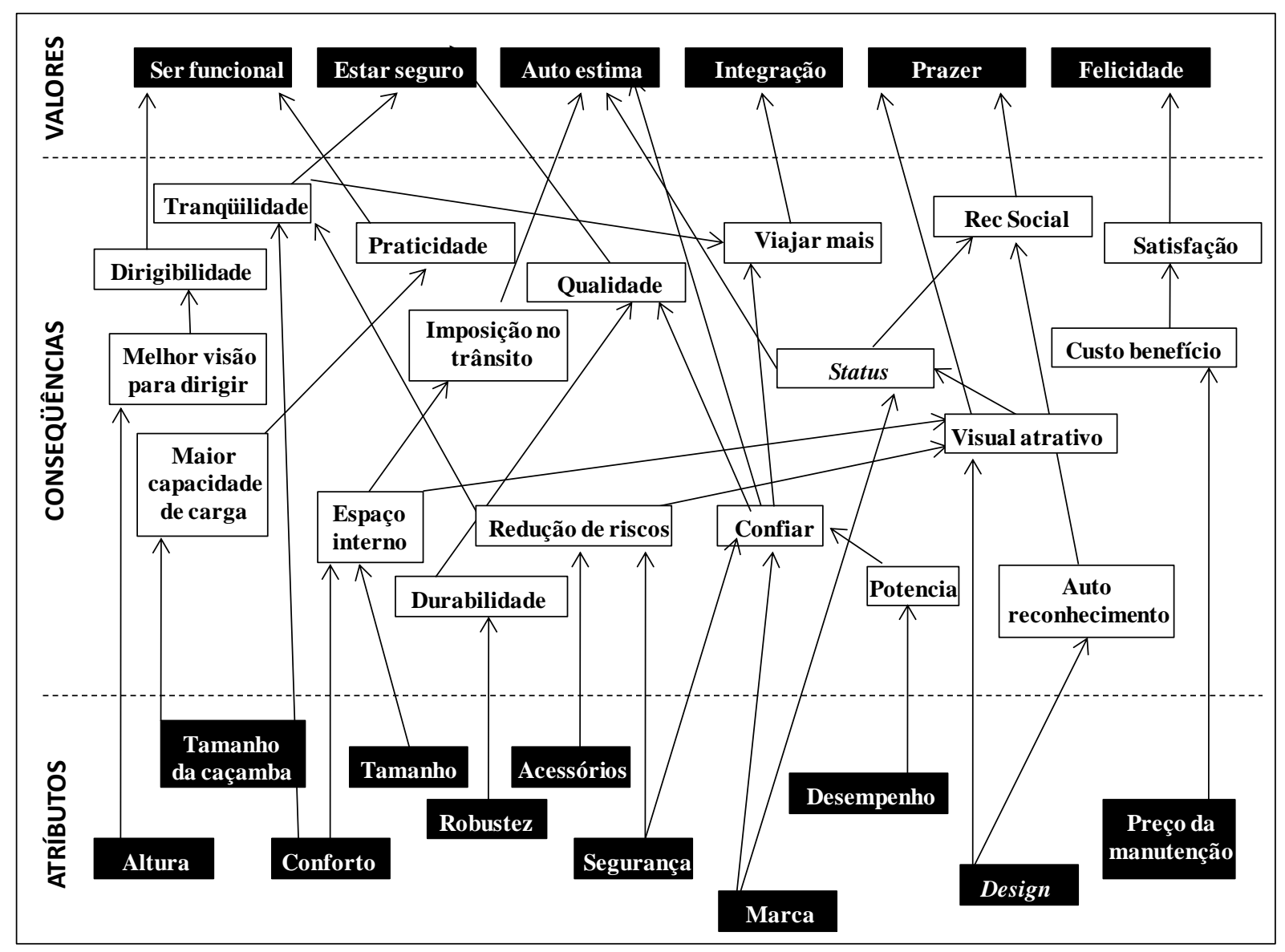

\subsection{DETERMINAÇÕES DAS PERCEPÇÕES SIGNIFICANTES DE VALOR}

Ao observar o mapa hierárquico de valor, é possível destacar algumas cadeias de valor que possuem maior relevância entre os entrevistados. A marca possui ligações com "status", "confiar na picape", "qualidade", "viajar mais", "reconhecimento pessoal", até chegar aos valores "prazer", "autoestima", "integração" e "estar seguro". Essa cadeia demonstra que a marca é de fundamental importância para os consumidores no momento de decisão de compra, pois este atributo gera

REMark - Revista Brasileira de Marketing, São Paulo, v. 10, n. 1, p 73-96, jan./abr. 2011. 
diversas consequências importantes para o cliente, que, por sua vez, forma um conjunto de valor para os clientes. Pode-se dizer que o consumidor pode possuir algum receio sobre uma marca pouco conhecida ou que não tem uma imagem de qualidade no mercado, portanto, ter uma boa imagem da marca é fundamental para que uma empresa possa atrair novos consumidores.

A segurança também apresenta forte relação no mapa hierárquico de valor, ela tem ligações com "redução de riscos", "confiar na caminhonete", "qualidade", "tranquilidade", "viajar mais" até os valores "estar seguro", “autoestima”, "integração”. O grupo pesquisado possui uma grande preocupação com a sua segurança e de seus entes queridos, por isso optam por um veículo seguro para que possam viajar com seus familiares com mais tranquilidade, aumentando as suas relações pessoais, a frequência de viagens e passeios e também sua autoestima.

O design se mostrou muito importante para os consumidores, pois leva à consequência "visual atrativo", "status", "reconhecimento social” e aos valores "prazer" e "autoestima". O design estabelece forte ligação com o valor autoestima, por isso notou-se que os consumidores buscam um veículo bonito, moderno, para que sejam reconhecidos socialmente e atinjam o valor autoestima. Cabe ressaltar que os entrevistados associam o design diretamente à beleza, por mais que seu real significado não seja este.

Adicionalmente, pôde-se notar que alguns itens possuíram alto grau de conectividade e estavam posicionados estrategicamente no centro do mapa. O elemento "confiar na caminhonete" tem grande importância, pois ele é responsável por possibilitar que os elementos "marca" e "segurança" consigam chegar ao valor "estar seguro". O "visual atrativo" foi responsável por possibilitar que os elementos "conforto" e "design" obtivessem os seus valores "autoestima" e "prazer". O item "espaço interno" também se mostrou importante ao conectar os atributos “conforto" e "tamanho" para que se conseguisse obter os valores "autoestima" e "prazer".

No lado esquerdo, podemos destacar os atributos "altura" e "tamanho da caçamba", que passando pelos elementos "maior capacidade de carga" e "melhor visão para dirigir", e pelas consequências "praticidade" e "dirigibilidade", levam ao valor "ser funcional". Este item atrai diretamente consumidores que necessitam de uma camionhnete funcional, para uso cotidiano, e que ao mesmo tempo possua capacidade de carga para viagens e passeios.

REMark - Revista Brasileira de Marketing, São Paulo, v. 10, n. 1, p 73-96, jan./abr. 2011. 


\section{CONSIDERAÇÕES FINAIS}

O objetivo principal desta pesquisa foi compreender melhor os consumidores de caminhonetes picapes médias, através da correlação dos atributos, consequências e valores. Para que a percepção de valor dos clientes fosse detectada, a realização deste estudo foi procedida com o método laddering, que se mostrou objetivo para estabelecer as correlações, ainda que possa haver algumas variações nas respostas dos entrevistados, pela demora da entrevista e por sua característica repetitiva, que são fatores limitadores.

Neste estudo procurou-se explorar e compreender melhor os consumidores de caminhonetes picapes de porte médio. Antigamente, esses veículos eram usados exclusivamente para trabalho ou pelos conhecidos "donos de fazenda", mas essa categoria de veículo passou a contar com uma nova geração de clientes, cada vez mais exigentes no momento da escolha de compra, e dessa forma as montadoras passaram a dedicar maior atenção para atender a esse mercado crescente, refletindo em enorme sucesso de vendas.

$\mathrm{O}$ estudo possibilitou descrever o perfil de consumidores de picapes. $\mathrm{O}$ grupo entrevistado possuía adeptos na faixa entre 37 e 56 anos e era composto por indivíduos com famílias maiores, casados ou comprometidos e de classe econômica média (B1 e B2). A maioria dos entrevistados eram homens que possuem família, todos os entrevistados moram e trabalham na região metropolitana de Porto Alegre. Quase a totalidade do grupo visa à segurança e ao bem-estar da família, amigos e entes queridos, e utiliza a picape no dia a dia e em viagens. O número de entrevistados que compra com o intuito de aventurar-se é muito pequeno e praticamente irrelevante ao analisarmos no conjunto. A robustez e a resistência continuam sendo diferenciais das picapes, mas pode-se ver uma maior inclinação dos consumidores para diferenciais que antes eram apenas dos carros sedãs de luxo, como: espaço interno, visual, conforto e tecnologia.

Compreender o porquê do consumo desse tipo de produto e o que os consumidores querem com ele é essencial para que os fabricantes e vendedores consigam comunicar-se com maior eficiência, não se atendo somente à comunicação básica e pouco profunda a respeito dos atributos de seus veículos, ou até mesmo sem saber o que interfere na hora da compra.

Portanto, os entrevistados do referido estudo diferenciaram fatores que interferem na hora da compra, sendo alguns dos mais importantes atributos e consequências ligados aos valores autoestima, prazer, ser funcional e estar seguro.

REMark - Revista Brasileira de Marketing, São Paulo, v. 10, n. 1, p 73-96, jan./abr. 2011. 
A grande maioria dos entrevistados acredita que a sua autoestima está diretamente relacionada com o design, visual atrativo, tamanho e o relacionamento social proporcionados por sua picape. São pessoas que estão fugindo de sedãs e fazem questão de ter luxo em um veículo grande e que dê status e segurança. No entanto, não colocariam suas picapes para fazer uma trilha. Esse consumidor, morador de grandes cidades, opta por um veículo forte e imponente para encarar o trânsito e as condições das vias urbanas, mas não dispensa o conforto de um carro de passeio, já que está sujeito a congestionamentos e também utiliza seu veículo para passear com a família nos fins de semana.

Este tipo de pesquisa proporciona melhor entendimento dos objetivos de vida, preocupações, intenções e valores dos consumidores de determinado segmento de mercado, permitindo, dessa forma, que a indústria priorize os atributos e consequências apontados como mais importantes. O método laddering surge especialmente para cooperar com a indústria no sentido de direcionar sua estratégia de comunicação com o mercado, fornecendo dados como "o que" comunicar, "como" e "para quem" fazê-lo.

\subsection{IMPLICAÇÕES GERENCIAIS E ACADÊMICAS}

Constata-se nesta pesquisa que as estratégias de mercado das empresas da indústria automotiva para o aumento de suas vendas e também para a obtenção de market-share passam, necessariamente, por investimentos que visem proporcionar uma experiência para este público em estudo, que contemple seus valores pessoais; sua necessidade de bem-estar; do aumento de sua qualidade de vida, e de sua carência em estar com a autoestima elevada. Os gestores deste segmento podem ter um reconhecimento maior desse nicho, realizando ações adequadas às necessidades dos seus clientes, de modo a contribuir para a consolidação e o desenvolvimento do setor, e assim influenciar positivamente (o consumidor) através de campanhas de comunicação com sua marca, criando uma identificação com este público que tende a retribuir com o consumo de seus produtos.

Acredita-se também que exista uma carência de estudos relativos a este setor, as pesquisas bibliográficas apontaram essa característica. Sendo assim, um maior incremento de pesquisas pode colaborar com o desenvolvimento do setor de picapes como negócios no país.

REMark - Revista Brasileira de Marketing, São Paulo, v. 10, n. 1, p 73-96, jan./abr. 2011. 


\subsection{LIMITAÇÕES DO ESTUDO E SUGESTÕES PARA PESQUISAS FUTURAS}

Como toda pesquisa, esta possui algumas limitações. Entre elas estão as limitações relativas ao método do modelo de Cadeias Meios-Fim, como o pequeno número de entrevistados, que é necessário já que é preciso um entrevistador treinado, além do tempo que é necessário para a aplicação da entrevista laddering. Existe também a grande interferência do entrevistador durante a fase qualitativa que pode influenciar ou até mesmo constranger o respondente. Normalmente as maiores dificuldades relativas a esta parte da pesquisa são originadas pela dificuldade que os respondentes têm de compreender seu próprio comportamento e motivação, e na carência de um entrevistador treinado, este pode simplesmente ser incapaz de revelar os dados necessários. Além disso, o entrevistador tem a dificuldade natural de saber se alcançou o ponto de abstração máximo ou até mesmo necessário de uma cadeia e quando este deve cessar de pressionar o consumidor para que ele aprofunde mais suas respostas.

Como sugestão de pesquisas futuras, o estudo referente à compra de picapes médias pode ser segmentado, de modo a estudar melhor aspectos relativos a serviços, aprofundando a análise nas áreas de eventos para esse tipo de consumidor. Decompondo, assim, a pesquisa nesta parte e outra, avaliando os produtos/equipamentos/tecnologias utilizados para o aperfeiçoamento das picapes médias, identificando a percepção que os consumidores têm especificamente desses elementos. Outra oportunidade existente seria a expansão da pesquisa para outras praças do País, para assim comparar a quantidade de caminhonetes picapes médias vendidas e até o valor percebido pelos clientes na hora da compra em cada um desses lugares, podendo, talvez, mapear esse mercado e utilizar esta informação como ferramenta de auxílio para uma possível estratégia de lançamento de um produto ou serviço para esses consumidores. Ainda seria possível uma comparação e diferenciação de clientes dos diferentes tipos de picapes (pequenas, médias e grandes).

REMark - Revista Brasileira de Marketing, São Paulo, v. 10, n. 1, p 73-96, jan./abr. 2011. 


\section{REFERÊNCIAS}

Associação Nacional dos Fabricantes de Veículos Automotores (2010). Disponível em: http://www.anfavea.com.br/Index.html. Acessado em: 17 de julho.

Federação Nacional da Distribuição de Veículos Automotores (2008). Anuário da Distribuição de Veículos Automotores no Brasil 2008. Recuperado em 15 outubro, 2010, de http://www.fenabrave.org.br/principal/home/?sistema=conteudos/conteudo\&id_conteudo=24\#co nteudo.

Federação Nacional da Distribuição de Veículos Automotores (2009). Anuário da Distribuição de Veículos Automotores no Brasil 2009. Recuperado em 15 outubro, 2010, de http://www.fenabrave.org.br/principal/home/?sistema=conteudos/conteudo\&id_conteudo=24\#co nteudo.

Foote, D., \& Lamb, K. (2002). Eliciting information about the values of HRM practitioners using laddering interviews. Business Ethics: A European Review, 11(3), 244-252.

Grunert, K. G., \& Grunert, S. C. (1995). Measuring subjective meaning structures by the laddering method: theoretical considerations and methodological problems. International Journal of Research in Marketing, 12(3), 209-225.

Gutman, J. (1982). A means-end chain model based on consumer categorization processes. Journal of Marketing, 46, 60-72.

Hinkle, D. (1965). The change of personal constructs from the viewpoint of theory of construct implications. Dissertação de Doutorado, Ohio State University, Columbus, OH, United States of America.

Hirschman, E. C., \& Holbrook, M. B. (1992). Postmodern consumer research: the study of consumption as text. Newbury Park, CA, USA: Sage.

Kaciak, E., \& Cullen, C. W. (2009). A method of abbreviating a laddering survey. Journal of Targeting, Measurement and Analysis for Marketing, 17, 105-113.

Morschetty, D., Swoboda, B., \& Scramm-Klein, H. (2006). Shopping orientations as determinants of attitude towards food retailers and perception of store attributes. European Advances in Consumer Research, 7, 160-167.

REMark - Revista Brasileira de Marketing, São Paulo, v. 10, n. 1, p 73-96, jan./abr. 2011. 
Radder, L., \& Grunert, K. G. (2009). Consumers perceptions of African wildlife meat: a laddering study. Journal of Food Products Marketing, 15(1), 164-174.

Reynolds, T. J., \& Gutman, J. (1988). Laddering theory, method, analysis, and interpretation. Journal of Advertising Research, 28, 11-31.

Reynolds, T., \& Whitlark, D. (1995). Applying laddering data to communications strategy and advertising practice. Journal of Advertising Research, 35, 9-16.

Richardson, R. J. (1999). Pesquisa Social: métodos e técnicas. São Paulo: Atlas.

Rugg, G., Eva, M., Mahmood, A., Rehman, N., Andrews, S., \& Davies, S. (2002). Eliciting information about organizational culture via laddering. Information Systems Journal, 12(1), 215229.

Sherman, E., Mathur, A., \& Smith, R. (1997). Store environment and consumer purchase behavior: mediating role of consumer emotions. Psychology and Marketing, 14(4), 361-378.

Sinha, P. K., \& Banerjee, A. (2004). Store choice behaviour in an evolving market. International Journal of Retail \& Distribution Management, 32(10), 482-494.

Vargo, S. L., \& Lusch, R. F. (2004). Evolving to a new dominant logic for marketing. Journal of Marketing, 68, 1-17.

Veludo-de-Oliveira, T. M., Ikeda, A. A., \& Campomar, M. C. (2006a). Discussing laddering application by the means-end chain theory. The Qualitative Report, 11(4), 626-642.

Veludo-de-Oliveira, T. M., Ikeda, A. A., \& Campomar, M. C. (2006b). Laddering in the practice of marketing research: barriers and solutions. Qualitative Market Research: An International Journal, 9(3), 297-306.

Woodruff, R. B., \& Gardial, S. F. (1996). Know your customer: new approaches to understanding customer value and satisfaction. Cambridge: Blackwell.

Zeithaml, V. A. (1988). Consumer perceptions of price, quality, and value: a means end model and synthesis of evidence. Journal of Marketing, 52, 2-22.

REMark - Revista Brasileira de Marketing, São Paulo, v. 10, n. 1, p 73-96, jan./abr. 2011. 


\title{
PERCEPTION OF VALUE THROUGH THE LADDERING TECHNIQUE: ANALYSIS OF THE AVERAGE PICKUP TRUCK CUSTOMERS
}

\begin{abstract}
The objective of the article is to identify the perceived value of average consumers of pickup trucks. We conducted exploratory, qualitative research with consumers located in the Greater Porto AlegreRS. We used laddering as a technique for collecting and analyzing data. The survey sample consisted of 13 respondents, this number being determined through theoretical saturation of the responses, with the identification of complete value chains. Data analysis was divided into four key steps: (a) compile data on individual attributes, consequences and values, (b) drafting table ladders, (c) creation of the matrix of commitment and hierarchical map of values and (d) definition of prevailing perceptions and the relationship that creates the perceived value of average consumers of pickup trucks.
\end{abstract}

Keywords: Laddering; Attributes; Consequences; Perceived Value.

Data do recebimento do artigo: 02/01/2011

Data do aceite de publicação: 24/02/2011

REMark - Revista Brasileira de Marketing, São Paulo, v. 10, n. 1, p 73-96, jan./abr. 2011. 